\title{
Essay
}

\section{Teaching Creativity and Inventive Problem Solving in Science}

\author{
Robert L. DeHaan
}

Division of Educational Studies, Emory University, Atlanta, GA 30322

Submitted December 31, 2008; Revised May 14, 2009; Accepted May 28, 2009

Monitoring Editor: Diane Ebert-May

\begin{abstract}
Engaging learners in the excitement of science, helping them discover the value of evidencebased reasoning and higher-order cognitive skills, and teaching them to become creative problem solvers have long been goals of science education reformers. But the means to achieve these goals, especially methods to promote creative thinking in scientific problem solving, have not become widely known or used. In this essay, I review the evidence that creativity is not a single hard-to-measure property. The creative process can be explained by reference to increasingly well-understood cognitive skills such as cognitive flexibility and inhibitory control that are widely distributed in the population. I explore the relationship between creativity and the higher-order cognitive skills, review assessment methods, and describe several instructional strategies for enhancing creative problem solving in the college classroom. Evidence suggests that instruction to support the development of creativity requires inquiry-based teaching that includes explicit strategies to promote cognitive flexibility. Students need to be repeatedly reminded and shown how to be creative, to integrate material across subject areas, to question their own assumptions, and to imagine other viewpoints and possibilities. Further research is required to determine whether college students' learning will be enhanced by these measures.
\end{abstract}

\section{INTRODUCTION}

Dr. Dunne paces in front of his section of first-year college students, today not as their Bio 110 teacher but in the role of facilitator in their monthly "invention session." For this meeting, the topic is stem cell therapy in heart disease. Members of each team of four students have primed themselves on the topic by reading selected articles from accessible sources such as Science, Nature, and Scientific American, and searching the World Wide Web, triangulating for up-to-date, accurate, background information. Each team knows that their first goal is to define a set of problems or limitations to overcome within the topic and to begin to think of possible solutions. Dr. Dunne starts the conversation by reminding the group of the few ground rules: one speaker at a time, listen carefully and have respect for others' ideas, question your own and others' assumptions, focus on alternative paths or solutions, maintain an atmosphere of collaboration and mutual

DOI: $10.1187 /$ cbe.08-12-0081

Address correspondence to: Robert L. DeHaan (rdehaan@emory. edu). support. He then sparks the discussion by asking one of the teams to describe a problem in need of solution.

Science in the United States is widely credited as a major source of discovery and economic development. According to the 2005 TAP Report produced by a prominent group of corporate leaders, "To maintain our country's competitiveness in the twenty-first century, we must cultivate the skilled scientists and engineers needed to create tomorrow's innovations." (www.tap2015.org/about/TAP_report2.pdf). A panel of scientists, engineers, educators, and policy makers convened by the National Research Council (NRC) concurred with this view, reporting that the vitality of the nation "is derived in large part from the productivity of well-trained people and the steady stream of scientific and technical innovations they produce" (NRC, 2007).

For many decades, science education reformers have promoted the idea that learners should be engaged in the excitement of science; they should be helped to discover the value of evidence-based reasoning and higher-order cognitive skills, and be taught to become innovative problem solvers (for reviews, see DeHaan, 2005; Hake, 2005; Nelson, 
2008; Perkins and Wieman, 2008). But the means to achieve these goals, especially methods to promote creative thinking in scientific problem solving, are not widely known or used. An invention session such as that led by the fictional Dr. Dunne, described above, may seem fanciful as a means of teaching students to think about science as something more than a body of facts and terms to memorize. In recent years, however, models for promoting creative problem solving were developed for classroom use, as detailed by Treffinger and Isaksen (2005), and such techniques are often used in the real world of high technology. To promote imaginative thinking, the advertising executive Alex F. Osborn invented brainstorming (Osborn, 1948, 1979), a technique that has since been successful in stimulating inventiveness among engineers and scientists. Could such strategies be transferred to a class for college students? Could they serve as a supplement to a high-quality, scientific teaching curriculum that helps students learn the facts and conceptual frameworks of science and make progress along the novice-expert continuum? Could brainstorming or other instructional strategies that are specifically designed to promote creativity teach students to be more adaptive in their growing expertise, more innovative in their problem-solving abilities? To begin to answer those questions, we first need to understand what is meant by "creativity."

\section{OVERVIEW}

\section{What Is Creativity? Big-C versus Mini-C Creativity}

How to define creativity is an age-old question. Justice Potter Stewart's famous dictum regarding obscenity "I know it when I see it" has also long been an accepted test of creativity. But this is not an adequate criterion for developing an instructional approach. A scientist colleague of mine recently noted that "Many of us [in the scientific community] rarely give the creative process a second thought, imagining one either 'has it' or doesn't." We often think of inventiveness or creativity in scientific fields as the kind of gift associated with a Michelangelo or Einstein. This is what Kaufman and Beghetto (2008) call big-C creativity, borrowing the term that earlier workers applied to the talents of experts in various fields who were identified as particularly creative by their expert colleagues (MacKinnon, 1978). In this sense, creativity is seen as the ability of individuals to generate new ideas that contribute substantially to an intellectual domain. Howard Gardner defined such a creative person as one who "regularly solves problems, fashions products, or defines new questions in a domain in a way that is initially considered novel but that ultimately comes to be accepted in a particular cultural setting" (Gardner, 1993, p. 35).

But there is another level of inventiveness termed by various authors as "little-c" (Craft, 2000) or "mini-c" (Kaufman and Beghetto, 2008) creativity that is widespread among all populations. This would be consistent with the workplace definition of creativity offered by Amabile and her coworkers: "coming up with fresh ideas for changing products, services and processes so as to better achieve the organization's goals" (Amabile et al., 2005). Mini-c creativity is based on what Craft calls "possibility thinking" (Craft, 2000, pp. 3-4), as experienced when a worker suddenly has the insight to visualize a new, improved way to accomplish a task; it is represented by the "aha" moment when a student first sees two previously disparate concepts or facts in a new relationship, an example of what Arthur Koestler identified as bisociation: "perceiving a situation or event in two habitually incompatible associative contexts" (Koestler, 1964, p. 95).

In this essay, I maintain that mini-c creativity is not a mysterious, innate endowment of rare individuals. Instead, I argue that creative thinking is a multicomponent process, mediated through social interactions, that can be explained by reference to increasingly well-understood mental abilities such as cognitive flexibility and cognitive control that are widely distributed in the population. Moreover, I explore some of the recent research evidence (though with no effort at a comprehensive literature review) showing that these mental abilities are teachable; like other higher-order cognitive skills (HOCS), they can be enhanced by explicit instruction.

\section{Creativity Is a Multicomponent Process}

Efforts to define creativity in psychological terms go back to J. P. Guilford (Guilford, 1950) and E. P. Torrance (Torrance, 1974), both of whom recognized that underlying the construct were other cognitive variables such as ideational fluency, originality of ideas, and sensitivity to missing elements. Many authors since then have extended the argument that a creative act is not a singular event but a process, an interplay among several interactive cognitive and affective elements. In this view, the creative act has two phases, a generative and an exploratory or evaluative phase (Finke et al., 1996). During the generative process, the creative mind pictures a set of novel mental models as potential solutions to a problem. In the exploratory phase, we evaluate the multiple options and select the best one. Early scholars of creativity, such as J. P. Guilford, characterized the two phases as divergent thinking and convergent thinking (Guilford, 1950). Guilford defined divergent thinking as the ability to produce a broad range of associations to a given stimulus or to arrive at many solutions to a problem (for overviews of the field from different perspectives, see Amabile, 1996; Banaji et al., 2006; Sawyer, 2006). In neurocognitive terms, divergent thinking is referred to as associative richness (Gabora, 2002; Simonton, 2004), which is often measured experimentally by comparing the number of words that an individual generates from memory in response to stimulus words on a word association test. In contrast, convergent thinking refers to the capacity to quickly focus on the one best solution to a problem.

The idea that there are two stages to the creative process is consistent with results from cognition research indicating that there are two distinct modes of thought, associative and analytical (Neisser, 1963; Sloman, 1996). In the associative mode, thinking is defocused, suggestive, and intuitive, revealing remote or subtle connections between items that may be correlated, or may not, and are usually not causally related (Burton, 2008). In the analytical mode, thought is focused and evaluative, more conducive to analyzing relationships of cause and effect (for a review of other cognitive aspects of creativity, see Runco, 2004). Science educators associate the analytical mode with the upper levels (analysis, synthesis, and evaluation) of Bloom's taxonomy (e.g., Crowe et al., 2008), or with "critical thinking," the process that underlies the "purposeful, self-regulatory judgment that 
drives problem-solving and decision-making" (Quitadamo et al., 2008, p. 328). These modes of thinking are under cognitive control through the executive functions of the brain. The core executive functions, which are thought to underlie all planning, problem solving, and reasoning, are defined (Blair and Razza, 2007) as working memory control (mentally holding and retrieving information), cognitive flexibility (considering multiple ideas and seeing different perspectives), and inhibitory control (resisting several thoughts or actions to focus on one). Readers wishing to delve further into the neuroscience of the creative process can refer to the cerebrocerebellar theory of creativity (Vandervert et al., 2007) in which these mental activities are described neurophysiologically as arising through interactions among different parts of the brain.

The main point from all of these works is that creativity is not some single hard-to-measure property or act. There is ample evidence that the creative process requires both divergent and convergent thinking and that it can be explained by reference to increasingly well-understood underlying mental abilities (Haring-Smith, 2006; Kim, 2006; Sawyer, 2006; Kaufman and Sternberg, 2007) and cognitive processes (Simonton, 2004; Diamond et al., 2007; Vandervert et al., 2007).

\section{Creativity Is Widely Distributed and Occurs in a Social Context}

Although it is understandable to speak of an aha moment as a creative act by the person who experiences it, authorities in the field have long recognized (e.g., Simonton, 1975) that creative thinking is not so much an individual trait but rather a social phenomenon involving interactions among people within their specific group or cultural settings. "Creativity isn't just a property of individuals, it is also a property of social groups" (Sawyer, 2006, p. 305). Indeed, Osborn introduced his brainstorming method because he was convinced that group creativity is always superior to individual creativity. He drew evidence for this conclusion from activities that demand collaborative output, for example, the improvisations of a jazz ensemble. Although each musician is individually creative during a performance, the novelty and inventiveness of each performer's playing is clearly influenced, and often enhanced, by "social and interactional processes" among the musicians (Sawyer, 2006, p. 120). Recently, Brophy (2006) offered evidence that for problem solving, the situation may be more nuanced. He confirmed that groups of interacting individuals were better at solving complex, multipart problems than single individuals. However, when dealing with certain kinds of single-issue problems, individual problem solvers produced a greater number of solutions than interacting groups, and those solutions were judged to be more original and useful.

Consistent with the findings of Brophy (2006), many scholars acknowledge that creative discoveries in the real world such as solving the problems of cutting-edge science-which are usually complex and multipart-are influenced or even stimulated by social interaction among experts. The common image of the lone scientist in the laboratory experiencing a flash of creative inspiration is probably a myth from earlier days. As a case in point, the science historian Mara Beller analyzed the social processes that underlay some of the major discoveries of early twentieth-century quantum physics. Close examination of successive drafts of publications by members of the Copenhagen group revealed a remarkable degree of influence and collaboration among 10 or more colleagues, although many of these papers were published under the name of a single author (Beller, 1999). Sociologists Bruno Latour and Steve Woolgar's study (Latour and Woolgar, 1986) of a neuroendocrinology laboratory at the Salk Institute for Biological Studies make the related point that social interactions among the participating scientists determined to a remarkable degree what discoveries were made and how they were interpreted. In the laboratory, researchers studied the chemical structure of substances released by the brain. By analysis of the Salk scientists' verbalizations of concepts, theories, formulas, and results of their investigations, Latour and Woolgar showed that the structures and interpretations that were agreed upon, that is, the discoveries announced by the laboratory, were mediated by social interactions and power relationships among members of the laboratory group. By studying the discovery process in other fields of the natural sciences, sociologists and anthropologists have provided more cases that further illustrate how social and cultural dimensions affect scientific insights (for a thoughtful review, see Knorr Cetina, 1995).

In sum, when an individual experiences an aha moment that feels like a singular creative act, it may rather have resulted from a multicomponent process, under the influence of group interactions and social context. The process that led up to what may be sensed as a sudden insight will probably have included at least three diverse, but testable elements: 1) divergent thinking, including ideational fluency or cognitive flexibility, which is the cognitive executive function that underlies the ability to visualize and accept many ideas related to a problem; 2) convergent thinking or the application of inhibitory control to focus and mentally evaluate ideas; and 3) analogical thinking, the ability to understand a novel idea in terms of one that is already familiar.

\section{LITERATURE REVIEW}

\section{What Do We Know about How to Teach Creativity?}

The possibility of teaching for creative problem solving gained credence in the 1960s with the studies of Jerome Bruner, who argued that children should be encouraged to "treat a task as a problem for which one invents an answer, rather than finding one out there in a book or on the blackboard" (Bruner, 1965, pp. 1013-1014). Since that time, educators and psychologists have devised programs of instruction designed to promote creativity and inventiveness in virtually every student population: pre-K, elementary, high school, and college, as well as in disadvantaged students, athletes, and students in a variety of specific disciplines (for review, see Scott et al., 2004). Smith (1998) identified 172 instructional approaches that have been applied at one time or another to develop divergent thinking skills.

Some of the most convincing evidence that elements of creativity can be enhanced by instruction comes from work 
with young children. Bodrova and Leong (2001) developed the Tools of the Mind (Tools) curriculum to improve all of the three core mental executive functions involved in creative problem solving: cognitive flexibility, working memory, and inhibitory control. In a year-long randomized study of 5-yr-olds from low-income families in 21 preschool classrooms, half of the teachers applied the districts' balanced literacy curriculum (literacy), whereas the experimenters trained the other half to teach the same academic content by using the Tools curriculum (Diamond et al., 2007). At the end of the year, when the children were tested with a battery of neurocognitive tests including a test for cognitive flexibility (Durston et al., 2003; Davidson et al., 2006), those exposed to the Tools curriculum outperformed the literacy children by as much as $25 \%$ (Diamond et al., 2007). Although the Tools curriculum and literacy program were similar in academic content and in many other ways, they differed primarily in that Tools teachers spent $80 \%$ of their time explicitly reminding the children to think of alternative ways to solve a problem and building their executive function skills.

Teaching older students to be innovative also demands instruction that explicitly promotes creativity but is rigorously content-rich as well. A large body of research on the differences between novice and expert cognition indicates that creative thinking requires at least a minimal level of expertise and fluency within a knowledge domain (Bransford et al., 2000; Crawford and Brophy, 2006). What distinguishes experts from novices, in addition to their deeper knowledge of the subject, is their recognition of patterns in information, their ability to see relationships among disparate facts and concepts, and their capacity for organizing content into conceptual frameworks or schemata (Bransford et al., 2000; Sawyer, 2005).

Such expertise is often lacking in the traditional classroom. For students attempting to grapple with new subject matter, many kinds of problems that are presented in high school or college courses or that arise in the real world can be solved merely by applying newly learned algorithms or procedural knowledge. With practice, problem solving of this kind can become routine and is often considered to represent mastery of a subject, producing what Sternberg refers to as "pseudoexperts" (Sternberg, 2003). But beyond such routine use of content knowledge the instructor's goal must be to produce students who have gained the HOCS needed to apply, analyze, synthesize, and evaluate knowledge (Crowe et al., 2008). The aim is to produce students who know enough about a field to grasp meaningful patterns of information, who can readily retrieve relevant knowledge from memory, and who can apply such knowledge effectively to novel problems. This condition is referred to as adaptive expertise (Hatano and Ouro, 2003; Schwartz et al., 2005). Instead of applying already mastered procedures, adaptive experts are able to draw on their knowledge to invent or adapt strategies for solving unique or novel problems within a knowledge domain. They are also able, ideally, to transfer conceptual frameworks and schemata from one domain to another (e.g., Schwartz et al., 2005). Such flexible, innovative application of knowledge is what results in inventive or creative solutions to problems (Crawford and Brophy, 2006; Crawford, 2007).

\section{Promoting Creative Problem Solving in the College Classroom}

In most college courses, instructors teach science primarily through lectures and textbooks that are dominated by facts and algorithmic processing rather than by concepts, principles, and evidence-based ways of thinking. This is despite ample evidence that many students gain little new knowledge from traditional lectures (Hrepic et al., 2007). Moreover, it is well documented that these methods engender passive learning rather than active engagement, boredom instead of intellectual excitement, and linear thinking rather than cognitive flexibility (e.g., Halpern and Hakel, 2003; Nelson, 2008; Perkins and Wieman, 2008). Cognitive flexibility, as noted, is one of the three core mental executive functions involved in creative problem solving (Ausubel, 1963, 2000). The capacity to apply ideas creatively in new contexts, referred to as the ability to "transfer" knowledge (see Mestre, 2005), requires that learners have opportunities to actively develop their own representations of information to convert it to a usable form. Especially when a knowledge domain is complex and fraught with ill-structured information, as in a typical introductory college biology course, instruction that emphasizes active-learning strategies is demonstrably more effective than traditional linear teaching in reducing failure rates and in promoting learning and transfer (e.g., Freeman et al., 2007). Furthermore, there is already some evidence that inclusion of creativity training as part of a college curriculum can have positive effects. Hunsaker (2005) has reviewed a number of such studies. He cites work by McGregor (2001), for example, showing that various creativity training programs including brainstorming and creative problem solving increase student scores on tests of creativethinking abilities.

What explicit instructional strategies are available to promote creative problem solving? In addition to brainstorming, McFadzean (2002) discusses several "paradigm-stretching" techniques that can encourage creative ideas. One method, known as heuristic ideation, encourages participants to force together two unrelated concepts to discover novel relationships, a modern version of Koestler's bisociation (Koestler, 1964). On the website of the Center for Development and Learning, Robert Sternberg and Wendy M. Williams offer 24 "tips" for teachers wishing to promote creativity in their students (Sternberg and Williams, 1998). Among them, the following techniques might apply to a science classroom:

- Model creativity-students develop creativity when instructors model creative thinking and inventiveness.

- Repeatedly encourage idea generation-students need to be reminded to generate their own ideas and solutions in an environment free of criticism.

- Cross-fertilize ideas-where possible, avoid teaching in subject-area boxes: a math box, a social studies box, etc; students' creative ideas and insights often result from learning to integrate material across subject areas.

- Build self-efficacy - all students have the capacity to create and to experience the joy of having new ideas, but they must be helped to believe in their own capacity to be creative.

- Constantly question assumptions-make questioning a part of the daily classroom exchange; it is more important 
for students to learn what questions to ask and how to ask them than to learn the answers.

- Imagine other viewpoints—students broaden their perspectives by learning to reflect upon ideas and concepts from different points of view.

Although these strategies are all consistent with the knowledge about creativity that I have reviewed above, evidence from well-designed investigations to warrant the claim that they can enhance measurable indicators of creativity in college students is only recently beginning to materialize. If creativity most often occurs in "a mental state where attention is defocused, thought is associative, and a large number of mental representations are simultaneously activated" (Martindale, 1999, p. 149), the question arises whether instructional strategies designed to enhance the HOCS also foster such a mental state? Do valid tests exist to show that creative problem solving can be enhanced by such instruction?

\section{How Is Creativity Related to Critical Thinking and the Higher-Order Cognitive Skills?}

It is not uncommon to associate creativity and ingenuity with scientific reasoning (Sawyer, 2005; 2006). When instructors apply scientific teaching strategies (Handelsman et al., 2004; DeHaan, 2005; Wood, 2009) by using instructional methods based on learning research, according to Ebert-May and Hodder (2008), "we see students actively engaged in the thinking, creativity, rigor, and experimentation we associate with the practice of science-in much the same way we see students learn in the field and in laboratories" (p. 2). Perkins and Wieman (2008) note that "To be successful innovators in science and engineering, students must develop a deep conceptual understanding of the underlying science ideas, an ability to apply these ideas and concepts broadly in different contexts, and a vision to see their relevance and usefulness in real-world applications... An innovator is able to perceive and realize potential connections and opportunities better than others" (pp. 181-182). The results of Scott et al. (2004) suggest that nontraditional courses in science that are based on constructivist principles and that use strategies of scientific teaching to promote the HOCS and enhance content mastery and dexterity in scientific thinking (Handelsman et al., 2007; Nelson, 2008) also should be effective in promoting creativity and cognitive flexibility if students are explicitly guided to learn these skills.

Creativity is an essential element of problem solving (Mumford et al., 1991; Runco, 2004) and of critical thinking (Abrami et al., 2008). As such, it is common to think of applications of creativity such as inventiveness and ingenuity among the HOCS as defined in Bloom's taxonomy (Crowe et al., 2008). Thus, it should come as no surprise that creativity, like other elements of the HOCS, can be taught most effectively through inquiry-based instruction, informed by constructivist theory (Ausubel, 1963, 2000; Duch et al., 2001; Nelson, 2008). In a survey of 103 instructors who taught college courses that included creativity instruction, Bull et al. (1995) asked respondents to rate the importance of various course characteristics for enhancing student creativity. Items ranking high on the list were: providing a social climate in which students feels safe, an open classroom environment that promotes tolerance for ambiguity and independence, the use of humor, metaphorical thinking, and problem defining. Many of the responses emphasized the same strategies as those advanced to promote creative problem solving (e.g., Mumford et al., 1991; McFadzean, 2002; Treffinger and Isaksen, 2005) and critical thinking (Abrami et al., 2008).

In a careful meta-analysis, Scott et al. (2004) examined 70 instructional interventions designed to enhance and measure creative performance. The results were striking. Courses that stressed techniques such as critical thinking, convergent thinking, and constraint identification produced the largest positive effect sizes. More open techniques that provided less guidance in strategic approaches had less impact on the instructional outcomes. A striking finding was the effectiveness of being explicit; approaches that clearly informed students about the nature of creativity and offered clear strategies for creative thinking were most effective. Approaches such as social modeling, cooperative learning, and case-based (project-based) techniques that required the application of newly acquired knowledge were found to be positively correlated to high effect sizes. The most clear-cut result to emerge from the Scott et al. (2004) study was simply to confirm that creativity instruction can be highly successful in enhancing divergent thinking, problem solving, and imaginative performance. Most importantly, of the various cognitive processes examined, those linked to the generation of new ideas such as problem finding, conceptual combination, and idea generation showed the greatest improvement. The success of creativity instruction, the authors concluded, can be attributed to "developing and providing guidance concerning the application of requisite cognitive capacities... [and] a set of heuristics or strategies for working with already available knowledge" (p. 382).

Many of the scientific teaching practices that have been shown by research to foster content mastery and HOCS, and that are coming more widely into use, also would be consistent with promoting creativity. Wood (2009) has recently reviewed examples of such practices and how to apply them. These include relatively small modifications of the traditional lecture to engender more active learning, such as the use of concept tests and peer instruction (Mazur, 1996), Just-in-Time-Teaching techniques (Novak et al., 1999), and student response systems known as "clickers" (Knight and Wood, 2005; Crossgrove and Curran, 2008), all designed to allow the instructor to frequently and effortlessly elicit and respond to student thinking. Other strategies can transform the lecture hall into a workshop or studio classroom (Gaffney et al., 2008) where the teaching curriculum may emphasize problem-based (also known as project-based or case-based) learning strategies (Duch et al., 2001; Ebert-May and Hodder, 2008) or "community-based inquiry" in which students engage in research that enhances their criticalthinking skills (Quitadamo et al., 2008).

Another important approach that could readily subserve explicit creativity instruction is the use of computer-based interactive simulations, or "sims" (Perkins and Wieman, 2008) to facilitate inquiry learning and effective, easy selfassessment. An example in the biological sciences would be Neurons in Action (http://neuronsinaction.com/home/ main). In such educational environments, students gain conceptual understanding of scientific ideas through interactive 
engagement with materials (real or virtual), with each other, and with instructors. Following the tenets of scientific teaching, students are encouraged to pose and answer their own questions, to make sense of the materials, and to construct their own understanding. The question I pose here is whether an additional focus-guiding students to meet these challenges in a context that explicitly promotes creativity-would enhance learning and advance students' progress toward adaptive expertise?

\section{Assessment of Creativity}

To teach creativity, there must be measurable indicators to judge how much students have gained from instruction. Educational programs intended to teach creativity became popular after the Torrance Tests of Creative Thinking (TTCT) was introduced in the 1960s (Torrance, 1974). But it soon became apparent that there were major problems in devising tests for creativity, both because of the difficulty of defining the construct and because of the number and complexity of elements that underlie it. Tests of intelligence and other personality characteristics on creative individuals revealed a host of related traits such as verbal fluency, metaphorical thinking, flexible decision making, tolerance of ambiguity, willingness to take risks, autonomy, divergent thinking, self-confidence, problem finding, ideational fluency, and belief in oneself as being "creative" (Barron and Harrington, 1981; Tardif and Sternberg, 1988; Runco and Nemiro, 1994; Snyder et al., 2004). Many of these traits have been the focus of extensive research of recent decades, but, as noted above, creativity is not defined by any one trait; there is now reason to believe that it is the interplay among the cognitive and affective processes that underlie inventiveness and the ability to find novel solutions to a problem.

Although the early creativity researchers recognized that assessing divergent thinking as a measure of creativity required tests for other underlying capacities (Guilford, 1950; Torrance, 1974), these workers and their colleagues nonetheless believed that a high score for divergent thinking alone would correlate with real creative output. Unfortunately, no such correlation was shown (Barron and Harrington, 1981). Results produced by many of the instruments initially designed to measure various aspects of creative thinking proved to be highly dependent on the test itself. A review of several hundred early studies showed that an individual's creativity score could be affected by simple test variables, for example, how the verbal pretest instructions were worded (Barron and Harrington, 1981, pp. 442-443). Most scholars now agree that divergent thinking, as originally defined, was not an adequate measure of creativity. The process of creative thinking requires a complex combination of elements that include cognitive flexibility, memory control, inhibitory control, and analogical thinking, enabling the mind to free-range and analogize, as well as to focus and test.

More recently, numerous psychometric measures have been developed and empirically tested (see Plucker and Renzulli, 1999) that allow more reliable and valid assessment of specific aspects of creativity. For example, the creativity quotient devised by Snyder et al. (2004) tests the ability of individuals to link different ideas and different categories of ideas into a novel synthesis. The Wallach-
Kogan creativity test (Wallach and Kogan, 1965) explores the uniqueness of ideas associated with a stimulus. For a more complete list and discussion, see the Creativity Tests website (www.indiana.edu/ bobweb/Handout/cretv_6.html).

The most widely used measure of creativity is the TTCT, which has been modified four times since its original version in 1966 to take into account subsequent research. The TTCTVerbal and the TTCT-Figural are two versions (Torrance, 1998; see http://ststesting.com/2005giftttct.html). The TTCT-Verbal consists of five tasks; the "stimulus" for each task is a picture to which the test-taker responds briefly in writing. A sample task that can be viewed from the TTCT Demonstrator website asks, "Suppose that people could transport themselves from place to place with just a wink of the eye or a twitch of the nose. What might be some things that would happen as a result? You have 3 min." (www. indiana.edu/ bobweb/Handout/d3.ttct.htm).

In the TTCT-Figural, participants are asked to construct a picture from a stimulus in the form of a partial line drawing given on the test sheet (see example below; Figure 1). Specific instructions are to "Add lines to the incomplete figures below to make pictures out of them. Try to tell complete stories with your pictures. Give your pictures titles. You have $3 \mathrm{~min} . "$ In the introductory materials, test-takers are urged to "... think of a picture or object that no one else will think of. Try to make it tell as complete and as interesting a story as you can ..." (Torrance et al., 2008, p. 2).

How would an instructor in a biology course judge the creativity of students' responses to such an item? To assist in this task, the TTCT has scoring and norming guides (Torrance, 1998; Torrance et al., 2008) with numerous samples and responses representing different levels of creativity. The guides show sample evaluations based upon specific indicators such as fluency, originality, elaboration (or complexity), unusual visualization, extending or breaking boundaries, humor, and imagery. These examples are easy to use and provide a high degree of validity and generalizability to the tests. The TTCT has been more intensively researched and analyzed than any other creativity instrument, and the norming samples have longitudinal validations and high predictive validity over a wide age range. In addition to global creativity scores, the TTCT is designed to provide outcome measures in various domains and thematic areas to allow for more insightful analysis (Kaufman and Baer, 2006). Kim (2006) has examined the characteristics of the TTCT,

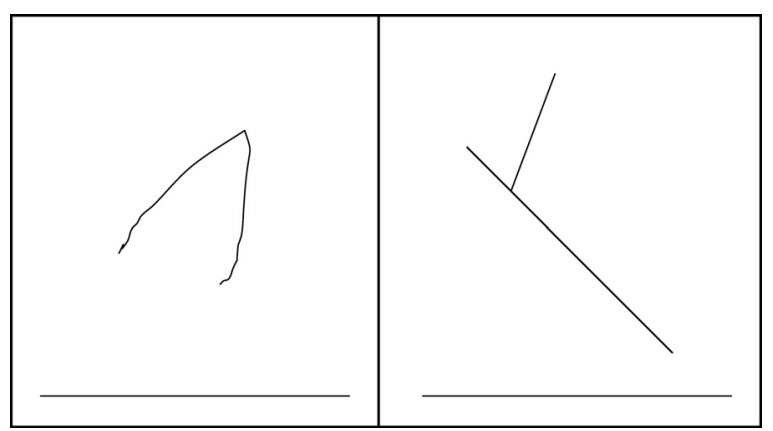

Figure 1. Sample figural test item from the TTCT Demonstrator website (www.indiana.edu/ bobweb/Handout/d3.ttct.htm). 
including norms, reliability, and validity, and concludes that the test is an accurate measure of creativity. When properly used, it has been shown to be fair in terms of gender, race, community status, and language background. According to Kim (2006) and other authorities in the field (McIntyre et al., 2003; Scott et al., 2004), Torrance's research and the development of the TTCT have provided groundwork for the idea that creative levels can be measured and then increased through instruction and practice.

\section{SCIENTIFIC TEACHING TO PROMOTE CREATIVITY}

\section{How Could Creativity Instruction Be Integrated into Scientific Teaching?}

Guidelines for designing specific course units that emphasize HOCS by using strategies of scientific teaching are now available from the current literature. As an example, Karen Cloud-Hansen and colleagues (Cloud-Hansen et al., 2008) describe a course titled, "Ciprofloxacin Resistance in Neisseria gonorrhoeae." They developed this undergraduate seminar to introduce college freshmen to important concepts in biology within a real-world context and to increase their content knowledge and critical-thinking skills. The centerpiece of the unit is a case study in which teams of students are challenged to take the role of a director of a local public health clinic. One of the county commissioners overseeing the clinic is an epidemiologist who wants to know "how you plan to address the emergence of ciprofloxacin resistance in Neisseria gonorrhoeae" (p. 304). State budget cuts limit availability of expensive antibiotics and some laboratory tests to patients. Student teams are challenged to 1) develop a plan to address the medical, economic, and political questions such a clinic director would face in dealing with ciprofloxacin-resistant $N$. gonorrhoeae; 2 ) provide scientific data to support their conclusions; and 3) describe their clinic plan in a one- to two-page referenced written report.

Throughout the 3-wk unit, in accordance with the principles of problem-based instruction (Duch et al., 2001), course instructors encourage students to seek, interpret, and synthesize their own information to the extent possible. Students have access to a variety of instructional formats, and active-learning experiences are incorporated throughout the unit. These activities are interspersed among minilectures and give the students opportunities to apply new information to their existing base of knowledge. The active-learning activities emphasize the key concepts of the minilectures and directly confront common misconceptions about antibiotic resistance, gene expression, and evolution. Weekly classes include question/answer/discussion sessions to address student misconceptions and 20-min minilectures on such topics as antibiotic resistance, evolution, and the central dogma of molecular biology. Students gather information about antibiotic resistance in N. gonorrhoeae, epidemiology of gonorrhea, and treatment options for the disease, and each team is expected to formulate a plan to address ciprofloxacin resistance in $N$. gonorrhoeae.

In this project, the authors assessed student gains in terms of content knowledge regarding topics covered such as the role of evolution in antibiotic resistance, mechanisms of gene expression, and the role of oncogenes in human disease.
They also measured HOCS as gains in problem solving, according to a rubric that assessed self-reported abilities to communicate ideas logically, solve difficult problems about microbiology, propose hypotheses, analyze data, and draw conclusions. Comparing the pre- and posttests, students reported significant learning of scientific content. Among the thinking skill categories, students demonstrated measurable gains in their ability to solve problems about microbiology but the unit seemed to have little impact on their more general perceived problem-solving skills (Cloud-Hansen et al., 2008).

What would such a class look like with the addition of explicit creativity-promoting approaches? Would the gains in problem-solving abilities have been greater if during the minilectures and other activities, students had been introduced explicitly to elements of creative thinking from the Sternberg and Williams (1998) list described above? Would the students have reported greater gains if their instructors had encouraged idea generation with weekly brainstorming sessions; if they had reminded students to cross-fertilize ideas by integrating material across subject areas; built selfefficacy by helping students believe in their own capacity to be creative; helped students question their own assumptions; and encouraged students to imagine other viewpoints and possibilities? Of most relevance, could the authors have been more explicit in assessing the originality of the student plans? In an experiment that required college students to develop plans of a different, but comparable, type, Osborn and Mumford (2006) created an originality rubric (Figure 2) that could apply equally to assist instructors in judging student plans in any course. With such modifications, would student gains in problem-solving abilities or other HOCS

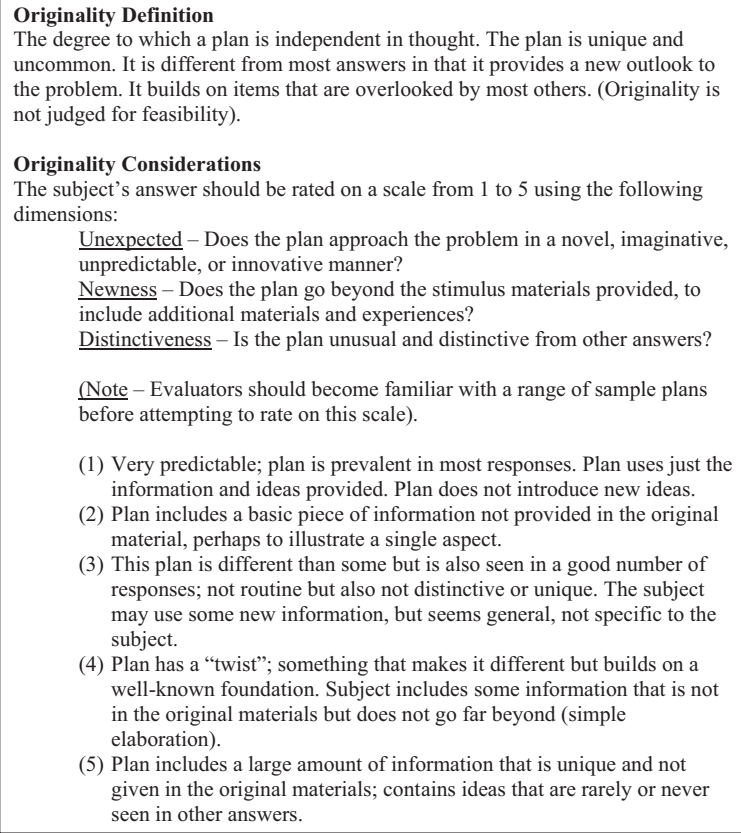

(1) Very predictable; plan is prevalent in most responses. Plan uses just the information and ideas provided. Plan does not introduce new ideas.

(2) Plan includes a basic piece of information not provided in the original material, perhaps to illustrate a single aspect.

(3) This plan is different than some but is also seen in a good number of responses; not routine but also not distinctive or unique. The subject may use some new information, but seems general, not specific to the subject.

(4) Plan has a "twist"; something that makes it different but builds on a well-known foundation. Subject includes some information that is not in the original materials but does not go far beyond (simple elaboration).

(5) Plan includes a large amount of information that is unique and not given in the original materials; contains ideas that are rarely or never seen in other answers.

Figure 2. Originality rubric (adapted from Osburn and Mumford, 2006, p. 183). 
have been greater? Would their plans have been measurably more imaginative?

Answers to these questions can only be obtained when a course like that described by Cloud-Hansen et al. (2008) is taught with explicit instruction in creativity of the type I described above. But, such answers could be based upon more than subjective impressions of the course instructors. For example, students could be pretested with items from the TTCT-Verbal or TTCT-Figural like those shown. If, during minilectures and at every contact with instructors, students were repeatedly reminded and shown how to be as creative as possible, to integrate material across subject areas, to question their own assumptions and imagine other viewpoints and possibilities, would their scores on TTCT posttest items improve? Would the plans they formulated to address ciprofloxacin resistance become more imaginative?

Recall that in their meta-analysis, Scott et al. (2004) found that explicitly informing students about the nature of creativity and offering strategies for creative thinking were the most effective components of instruction. From their careful examination of 70 experimental studies, they concluded that approaches such as social modeling, cooperative learning, and case-based (project-based) techniques that required the application of newly acquired knowledge were positively correlated with high effect sizes. The study was clear in confirming that explicit creativity instruction can be successful in enhancing divergent thinking and problem solving. Would the same strategies work for courses in ecology and environmental biology, as detailed by Ebert-May and Hodder (2008), or for a unit elaborated by Knight and Wood (2005) that applies classroom response clickers?

Finally, I return to my opening question with the fictional Dr. Dunne. Could a weekly brainstorming "invention session" included in a course like those described here serve as the site where students are introduced to concepts and strategies of creative problem solving? As frequently applied in schools of engineering (Paulus and Nijstad, 2003), brainstorming provides an opportunity for the instructor to pose a problem and to ask the students to suggest as many solutions as possible in a brief period, thus enhancing ideational fluency. Here, students can be encouraged explicitly to build on the ideas of others and to think flexibly. Would brainstorming enhance students' divergent thinking or creative abilities as measured by TTCT items or an originality rubric? Many studies have demonstrated that group interactions such as brainstorming, under the right conditions, can indeed enhance creativity (Paulus and Nijstad, 2003; Scott et al., 2004), but there is little information from an undergraduate science classroom setting. Intellectual Ventures, a firm founded by Nathan Myhrvold, the creator of Microsoft's Research Division, has gathered groups of engineers and scientists around a table for day-long sessions to brainstorm about a prearranged topic. Here, the method seems to work. Since it was founded in 2000, Intellectual Ventures has filed hundreds of patent applications in more than 30 technology areas, applying the "invention session" strategy (Gladwell, 2008). Currently, the company ranks among the top 50 worldwide in number of patent applications filed annually. Whether such a technique could be applied successfully in a college science course will only be revealed by future research.

\section{REFERENCES}

Abrami, P. C., Bernard, R. M., Borokhovski, E., Wadem, A., Surkes, M. A., Tamim, R., and Zhang, D. (2008). Instructional interventions affecting critical thinking skills and dispositions: a stage 1 metaanalysis. Rev. Educ. Res. 78, 1102-1134.

Amabile, T. M. (1996). Creativity in Context, Boulder, CO: Westview Press.

Amabile, T. M., Barsade, S. G., Mueller, J. S., and Staw, B. M. (2005). Affect and creativity at work. Admin. Sci. Q. 50, 367-403.

Ausubel, D. (1963). The Psychology of Meaningful Verbal Learning, New York: Grune and Stratton.

Ausubel, B. (2000). The Acquisition and Retention of Knowledge: A Cognitive View, Boston, MA: Kluwer Academic Publishers.

Banaji, S., Burn, A., and Buckingham, D. (2006). The Rhetorics of Creativity: A Review of the Literature, London: Centre for the Study of Children, Youth and Media. www.creativepartnerships.com/data/ files/rhetorics-of-creativity-12.pdf (accessed 29 December 2008).

Barron, F., and Harrington, D. M. (1981). Creativity, intelligence and personality. Ann. Rev. Psychol. 32, 439-476.

Beller, M. (1999). Quantum Dialogue: The Making of a Revolution, Chicago, IL: University of Chicago Press.

Blair, C., and Razza, R. P. (2007). Relating effortful control, executive function, and false belief understanding to emerging math and literacy ability in kindergarten. Child Dev. 78, 647-663.

Bodrova, E., and Leong, D. J. (2001). The Tool of the Mind: a case study of implementing the Vygotskian approach. In: American Early Childhood and Primary Classrooms, Geneva, Switzerland: UNESCO International Bureau of Education.

Bransford, J. D., Brown, A. L., and Cocking, R. R. (eds.). (2000). How People Learn: Brain, Mind, Experience, and School, Washington, DC: National Academies Press.

Brophy, D. R. (2006). A comparison of individual and group efforts to creatively solve contrasting types of problems. Creativity Res. J. $18,293-315$.

Bruner, J. (1965). The growth of mind. Am. Psychol. 20, 1007-1017.

Bull, K. S., Montgomery, D., and Baloche, L. (1995). Teaching creativity at the college level: a synthesis of curricular components perceived as important by instructors. Creativity Res. J. 8, 83-90.

Burton, R. (2008). On Being Certain: Believing You Are Right Even When You're Not, New York: St. Martin's Press.

Cloud-Hanson, K. A., Kuehner, J. N., Tong, L., Miller, S., and Handelsman, J. (2008). Money, sex and drugs: a case study to teach the genetics of antibiotic resistance. CBE Life Sci. Educ. 7, 302-309.

Craft, A. (2000). Teaching Creativity: Philosophy and Practice, New York: Routledge.

Crawford, V. M. (2007). Adaptive expertise as knowledge building in science teachers' problem solving. In: Proceedings of the Second European Cognitive Science Conference, Delphi, Greece. http://ctl.sri. com/publications/downloads/Crawford_EuroCogSci07Proceedings.pdf (accessed 1 July 2008).

Crawford, V. M., and Brophy, S. (2006). Adaptive Expertise: Theory, Methods, Findings, and Emerging Issues; September 2006, Menlo Park, CA: SRI International. http://ctl.sri.com/publications/downloads/AESymposiumReportOct06.pdf (accessed 1 July 2008).

Crossgrove, K., and Curran, K. L. (2008). Using clickers in nonmajors- and majors-level biology courses: student opinion, learning, and long-term retention of course material. CBE Life Sci. Educ. 7, $146-154$. 
Crowe, A., Dirks, C., and Wenderoth, M. P. (2008). Biology in bloom: implementing Bloom's taxonomy to enhance student learning in biology. CBE Life Sci. Educ. 7, 368-381.

Davidson, M. C., Amso, D., Anderson, L. C., and Diamond, A. (2006). Development of cognitive control and executive functions from 4-13 years: evidence from manipulations of memory, inhibition, and task switching. Neuropsychologia 44, 2037-2078.

DeHaan, R. L. (2005). The impending revolution in undergraduate science education. J. Sci. Educ. Technol. 14, 253-270.

Diamond, A., Barnett, W. S., Thomas, J., and Munro, S. (2007). Preschool program improves cognitive control. Science, 318, 13871388

Duch, B. J., Groh, S. E. and Allen, D. E. (2001). The Power of Problem-based Learning, Sterling, VA: Stylus Publishers.

Durston, S., Davidson, M. C., Thomas, K. M., Worden, M. S., Tottenham, N., Martinez, A., Watts, R., Ulug, A. M., and Caseya, B. J. (2003). Parametric manipulation of conflict and response competition using rapid mixed-trial event-related fMRI. Neuroimage 20, 2135-2141.

Ebert-May, D., and Hodder, J. (2008). Pathways to Scientific Teaching, Sunderland, MA: Sinauer.

Finke, R. A., Ward, T. B., and Smith, S. M. (1996). Creative Cognition: Theory, Research and Applications, Boston, MA: MIT Press.

Freeman, S., O'Connor, E., Parks, J. W., Cunningham, M., Hurley, D., Haak, D., Dirks, C., and Wenderoth, M. P. (2007). Prescribed active learning increases performance in introductory biology. CBE Life Sci. Educ. 6, 132-139.

Gabora, L. (2002). Cognitive mechanisms underlying the creative process. In: Proceedings of the Fourth International Conference on Creativity and Cognition, ed. T. Hewett and E. Kavanagh, 2002 October 13-16, Loughborough University, United Kingdom, 126 133

Gaffney, J.D.H., Richards, E., Kustusch, M. B., Ding, L., and Beichner, R. (2008). Scaling up education reform. J. Coll. Sci. Teach. 37, 48-53.

Gardner, H. (1993). Creating Minds: An Anatomy of Creativity Seen through the Lives of Freud, Einstein, Picasso, Stravinsky, Eliot, Graham, and Ghandi, New York: Harper Collins.

Gladwell, M. (2008). In the air; who says big ideas are rare? The New Yorker. www.newyorker.com/reporting/2008/05/12/080512fa_ fact_gladwell (accessed 19 May 2008).

Guilford, J. P. (1950). Creativity. Am. Psychol. 5, 444-454.

Hake, R. (2005). The physics education reform effort: a possible model for higher education. Natl. Teach. Learn. Forum 15, 1-6.

Halpern, D. E., and Hakel, M. D. (2003). Applying the science of learning to the university and beyond. Change 35, 36-42.

Handelsman, J., et al. (2004). Scientific teaching. Science 304, 521522.

Handelsman, J., Miller, S., and Pfund, C. (2007). Scientific Teaching, New York: W. H. Freeman and Co.

Haring-Smith, T. (2006). Creativity research review: some lessons for higher education. Association of American Colleges and Universities. Peer Rev. 8, 23-27.

Hatano, G., and Ouro, Y. (2003). Commentary: reconceptualizing school learning using insight from expertise research. Educ. Res. 32, 26-29.

Hrepic, Z., Zollman, D. A., and Rebello, N. S. (2007). Comparing students' and experts' understanding of the content of a lecture. J. Sci. Educ. Technol. 16, 213-224.

Hunsaker, S. L. (2005). Outcomes of creativity training programs. Gifted Child Q. 49, 292-298.
Kaufman, J. C., and Baer, J. (2006). Intelligent testing with Torrance Creativity Res. J. 18, 99-102.

Kaufman, J. C., and Beghetto, R. A. (2008). Exploring mini-C: creativity across cultures. In: Education for Innovation: Implications for India, China and America, ed. R. L. DeHaan and K.M.V. Narayan, Rotterdam, The Netherlands: Sense Publishers, 165-180.

Kaufman, J. C., and Sternberg, R. J. (2007). Creativity. Change, 39, 55-58.

Kim, K. H. (2006). Can we trust creativity tests: a review of the Torrance Tests of Creative Thinking (TTCT). Creativity Res. J. 18, 3-14.

Knight, J. K., and Wood, W. B. (2005). Teaching more by lecturing less. Cell Biol. Educ. 4, 298-310.

Knorr Cetina, K. (1995). Laboratory studies: the cultural approach to the study of science. In: Handbook of Science and Technology Studies, ed. S. Jasanoff, G. Markle, J. Petersen, and T. Pinch, Thousand Oaks, CA: Sage Publications, 140-166.

Koestler, A. (1964). The Act of Creation, New York: Macmillan.

Latour, B., and Woolgar, S. (1986). Laboratory Life: The Construction of Scientific Facts, Princeton, NJ: Princeton University Press.

MacKinnon, D. W. (1978). What makes a person creative? In: In Search of Human Effectiveness, ed. D. W. MacKinnon, New York: Universe Books, 178-186.

Martindale, C. (1999). Biological basis of creativity. In: Handbook of Creativity, ed. R. J. Sternberg, Cambridge, United Kingdom: Cambridge University Press, 137-152.

Mazur, E. (1996). Peer Instruction: A User's Manual, Upper Saddle River, NJ: Prentice Hall.

McFadzean, E. (2002). Developing and supporting creative problem-solving teams: Part 1-a conceptual model. Manage. Decis. 40, 463-475.

McGregor, G. D., Jr. (2001). Creative thinking instruction for a college study skills program: a case study. Dissert. Abstr. Intl. 62, 3293A. (UMI No. AAT 3027933).

McIntyre, F. S., Hite, R. E., and Rickard, M. K. (2003). Individual characteristics and creativity in the marketing classroom: exploratory insights. J. Mark. Educ. 25, 143-149.

Mestre, J. P. (ed.). (2005). Transfer of Learning: From a Modern Multidisciplinary Perspective, Greenwich, CT: Information Age Publishing.

Mumford, M. D., Mobley, M. I., Uhlman, C. E., Reiter-Palmon, R., and Doares, L. M. (1991). Process analytic models of creative capacities. Creativity Res. J. 4, 91-122.

National Research Council (2007). Rising Above the Gathering Storm: Energizing and Employing America for a Brighter Economic Future, Committee on Science, Engineering and Public Policy. Washington, DC: National Academies Press.

Neisser, U. (1963). The multiplicity of thought. Br. J. Psychol. 54, $1-14$.

Nelson, C. E. (2008). Teaching evolution (and all of biology) more effectively: strategies for engagement, critical reasoning, and confronting misconceptions. Integrative and Comparative Biology Advance Access. http://icb.oxfordjournals.org/cgi/reprint/icn027v1.pdf (accessed 15 September 2008)

Novak, G, Gavrin, A., Christian, W, and Patterson, E. (1999). Justin-Time Teaching: Blending Active Learning with Web Technology, San Francisco, CA: Pearson Benjamin Cummings.

Osborn, A. F. (1948). Your Creative Power, New York: Scribner.

Osborn, A. F. (1979). Applied Imagination, New York: Scribner. 
Osburn, H. K., and Mumford, M. D. (2006). Creativity and planning: training interventions to develop creative problem-solving skills. Creativity Res. J. 18, 173-190.

Paulus, P. B., and Nijstad B. A. (2003). Group Creativity: Innovation through Collaboration, New York: Oxford University Press.

Perkins, K. K., and Wieman, C. E. (2008). Innovative teaching to promote innovative thinking. In: Education for Innovation: Implications for India, China and America, ed. R. L. DeHaan and K.M.V. Narayan, Rotterdam, The Netherlands: Sense Publishers, 181-210.

Plucker, J. A., and Renzulli, J. S. (1999). Psychometric approaches to the study of human creativity. In: Handbook of Creativity, ed. R. J. Sternberg, Cambridge, United Kingdom: Cambridge University Press, 35-61.

Quitadamo, I. J., Faiola, C. L., Johnson, J. E., and Kurtz, M. J. (2008). Community-based inquiry improves critical thinking in general education biology. CBE Life Sci. Educ. 7, 327-337.

Runco, M. A. (2004). Creativity. Annu. Rev. Psychol. 55, 657-687.

Runco, M. A., and Nemiro, J. (1994). Problem finding, creativity, and giftedness. Roeper Rev. 16, 235-241.

Sawyer, R. K. (2005) Educating for Innovation. Thinking Skills Creativity 1, 41-48. www.artsci.wustl.edu/ ksawyer/PDFs/Thinkjournal.pdf (accessed 13 August 2008).

Sawyer, R. K. (2006). Explaining Creativity: The Science of Human Innovation, New York: Oxford University Press.

Schwartz, D. L., Bransford, J. D., and Sears, D. (2005) Efficiency and innovation in transfer. In: Transfer of Learning from a Modern Multidisciplinary Perspective, ed. J. P. Mestre, Greenwich, CT: Information Age Publishing, 1-51.

Scott, G., Leritz, L. E., and Mumford, M. D. (2004). The effectiveness of creativity training: a quantitative review. Creativity Res. J. 16, 361-388.

Simonton, D. K. (1975). Sociocultural context of individual creativity: a transhistorical time-series analysis. J. Pers. Soc. Psychol. 32, $1119-1133$.

Simonton, D. K. (2004) Creativity in Science: Chance, Logic, Genius, and Zeitgeist, Oxford, United Kingdom: Cambridge University Press.
Sloman, S. (1996) The empirical case for two systems of reasoning. Psychol. Bull. 9, 3-22.

Smith, G. F. (1998). Idea generation techniques: a formulary of active ingredients. J. Creative Behav. 32, 107-134.

Snyder, A., Mitchell, J., Bossomaier, T., and Pallier, G. (2004). The creativity quotient: an objective scoring of ideational fluency. Creativity Res. J. 16, 415-420.

Sternberg, R. J. (2003). What is an "expert student?" Educ. Res. 32, 5-9.

Sternberg, R., and Williams, W. M. (1998) Teaching for creativity: two dozen tips. www.cdl.org/resource-library/articles/teaching_creativity.php (accessed 25 March 2008).

Tardif, T. Z., and Sternberg, R. J. (1988). What do we know about creativity? In: The Nature of Creativity, ed. R. J. Sternberg, New York: Cambridge University Press, 429-440.

Torrance, E. P. (1974). Norms and Technical Manual for the Torrance Tests of Creative Thinking, Bensenville, IL: Scholastic Testing Service.

Torrance, E. P. (1998). The Torrance Tests of Creative Thinking Norms-Technical Manual Figural (Streamlined) Forms A and B, Bensenville, IL: Scholastic Testing Service.

Torrance, E. P., Ball, O. E., and Safter, H. T. (2008). Torrance Tests of Creative Thinking: Streamlined Scoring Guide for Figural Forms A and B, Bensenville, IL: Scholastic Testing Service.

Treffinger, D. J., and Isaksen, S. G. (2005). Creative problem solving: the history, development, and implications for gifted education and talent development. Gifted Child Q. 49, 342-357.

Vandervert, L. R., Schimpf, P. H., and Liu, H. (2007). How working memory and the cerebellum collaborate to produce creativity and innovation. Creativity Res. J. 9, 1-18.

Wallach, M. A., and Kogan, N. (1965). Modes of Thinking in Young Children: A Study of the Creativity-Intelligence Distinction, New York: Holt, Rinehart and Winston.

Wood, W. B. (2009). Innovations in undergraduate biology teaching and why we need them. Annu. Rev. Cell Dev. Biol. (in press). 